Southern Illinois University Carbondale

OpenSIUC

Publications

Department of Zoology

$2-2007$

\title{
Effects of Joint Space Use and Group Membership on Contact Rates Among White-Tailed Deer
}

Eric M. Schauber

Southern Illinois University Carbondale, schauber@siu.edu

Daniel J. Storm

Southern Illinois University Carbondale

Clayton K. Nielsen

Southern Illinois University Carbondale

Follow this and additional works at: http://opensiuc.lib.siu.edu/zool_pubs

This is the peer reviewed version of the article cited below, which has been published in final form at doi:10.2193.2005-546. This article may be used for non-commercial purposes in accordance with Wiley Terms and Conditions for Self-Archiving.

\section{Recommended Citation}

Schauber, Eric M., Storm, Daniel J. and Nielsen, Clayton K. "Effects of Joint Space Use and Group Membership on Contact Rates Among White-Tailed Deer." Journal of Wildlife Management 71, No. 1 (Feb 2007): 155-163. doi:10.2193.2005-546.

This Article is brought to you for free and open access by the Department of Zoology at OpenSIUC. It has been accepted for inclusion in Publications by an authorized administrator of OpenSIUC. For more information, please contact opensiuc@lib.siu.edu. 
123 August 2006

2 Eric M. Schauber

3 Cooperative Wildlife Research Laboratory

4 Southern Illinois University

5 Mailcode 6504

6 Carbondale, IL 62901

7 618-453-6940; FAX 618-453-6944; Email schauber@ siu.edu

8 RH: Contact rates in white-tailed deer $\bullet$ Schauber et al.

9 EFFECTS OF JOINT SPACE USE AND GROUP MEMBERSHIP ON CONTACT

10 RATES AMONG WHITE-TAILED DEER

11 ERIC M. SCHAUBER, ${ }^{1}$ Cooperative Wildlife Research Laboratory and Department of

12 Zoology, Southern Illinois University, Carbondale, IL 62901

13 DANIEL J. STORM, ${ }^{2}$ Cooperative Wildlife Research Laboratory and Department of

14 Zoology, Southern Illinois University, Carbondale, IL 62901

15 CLAYTON K. NIELSEN, Cooperative Wildlife Research Laboratory, Southern Illinois

16 University, Carbondale, IL 62901

17 Abstract: Establishment and spread of infectious diseases are controlled by the frequency

18 of contacts among hosts. Although managers can estimate transmission coefficients from

19 the relationship between disease prevalence and age or time, they may wish to quantify or

20 compare contact rates before a disease is established or while it is at very low prevalence.

21 Our objectives were to quantify direct and indirect contacts rates among white-tailed deer

22 (Odocoileus virginianus) and to compare these measures of contact rate with simpler

\footnotetext{
${ }^{1}$ E-mail: schauber@siu.edu

${ }^{2}$ Current address: Department of Wildlife Ecology, University of Wisconsin, Madison,
} WI 53706 
23 measures of joint space use. We deployed Global Positioning System (GPS) collars on 23

24 deer near Carbondale, Illinois from 2002 to 2005. We used location data from the GPS

25 collars to measure pairwise rates of direct and indirect contact, based on a range of

26 proximity criteria and time lags, as well as volume of intersection (VI) of kernel utilization

27 distributions. We analyzed contact rates at a given distance criterion and time lag using

28 mixed-model logistic regression. Direct contact rates increased with increasing VI and

29 were higher in fall-spring than in summer. After accounting for VI, the estimated odds of

30 direct contact during fall-spring periods were 5.0 to 22.1 -fold greater (depending on the

31 proximity criterion) for pairs of deer in the same social group than for between-group

32 pairs, but for direct contacts during summer the within:between-group odds ratio did not

33 differ significantly from 1 . Indirect contact rates also increased with VI, but the effects of

34 both season and pair-type were much smaller than for direct contacts and differed little as

35 the time lag increased from 1 to $30 \mathrm{~d}$. These results indicate that simple measures of joint

36 space use are insufficient indices of direct contact because group membership can

37 substantially increase contacts at a given level of joint space use. With indirect

38 transmission, however, group membership had a much smaller influence after accounting

39 for VI. Relationships between contact rates and season, VI, and pair type were generally

40 robust to changes in the proximity criterion defining a contact, and patterns of indirect

41 contacts were affected little by the choice of time lag from 1 to $30 \mathrm{~d}$. The use of GPS

42 collars provides a framework for testing hypotheses about the form of contact networks

43 among large mammals and comparing potential direct and indirect contact rates across

44 gradients of ecological factors, such as population density or landscape configuration. 
46 Key words: contact rate, disease, Global Positioning System, home range, Illinois,

47 Odocoileus virginianus, social behavior, space use, transmission, white-tailed deer.

49 Contact rates fundamentally influence the establishment and spread of infectious diseases, 50 and are sensitive to ecological setting (Anderson and May 1986). Some diseases, such as

51 bovine tuberculosis (Cheeseman et al. 1988a, Lugton et al. 1998, O'Brien et al. 2002),

52 require close physical proximity or near-simultaneous use of a site for transmission. The

53 agent of chronic wasting disease (CWD) can similarly be transmitted directly (Miller and

54 Williams 2003) but also appears to be transmitted indirectly, remaining infective for

55 months to years in the environment (Miller et al. 1998, Williams et al. 2002, Miller et al.

56 2004). Whether transmission occurs primarily via direct or indirect contact, contact rates

57 among wild animals can be elevated by high population density (Dietz 1982, de Jong et al.

58 2002, Ramsey et al. 2002), spatially concentrated resources such as cover or food (Totton

59 et al. 2002, Palmer et al. 2004), and living in a social group (Altizer et al. 2003). Because

60 contact rates are so important in the ecology of wildlife diseases, methods to measure

61 contact rates would be useful to researchers and managers. Past researchers have

62 quantified contact rates by observing contacts visually (Totton et al. 2002) or using

63 telemetry to infer how often animals come in close proximity (White and Harris 1994,

64 Caley et al. 1998, Ramsey et al. 2002, White et al. 2003, Ji et al. 2005). 
67 numbers of locations of high spatial and temporal precision (Di Orio et al. 2003) for

68 individual animals. Researchers using GPS telemetry can compare locations of multiple

69 animals simultaneously with high precision, enabling measurement of direct contact rate.

70 Researchers can also measure indirect contact rates by measuring how often each animal

71 approaches sites visited in the past by other animals. Of course, close proximity of 2 hosts

72 (either simultaneously or separated in time) or even physical touching does not necessarily

73 indicate that contact sufficient for disease transmission has occurred. However, probability

74 of disease transmission should logically increase as the frequency at which hosts come in

75 close proximity increases.

76 The high cost of GPS collars can severely limit the number of animals that

77 managers can monitor with such high precision and intensity. An alternative approach

78 would be to use joint space use (e.g., home range overlap or volume of intersection of

79 utilization distributions; Millspaugh et al. 2004) as a measure of potential contact between

80 pairs of hosts. For example, Conner and Miller (2004) evaluated potential contact between

812 mule deer (Odocoileus hemionus) population units by the frequency at which members

82 of 1 unit were located within the home range of the other unit. Because joint space use

83 may be cheaper and easier to quantify than the frequency at which 2 animals come in close

84 proximity, such an index of potential contact may provide an efficient metric for

85 management decisions. However, social structure can also affect contact rates, and may

86 preclude the utility of joint space use as an index of contact.

87 Group-living animals are more likely to contact other individuals within their social

88 group than those from other groups. In cases where group membership is stable and 
89 well-defined, as with European badgers (Meles meles; Cheeseman et al. 1988b), managers

90 could treat groups as if they were individuals, with the assumption that 1 infected member

91 is likely to infect the entire group. However, lethal population control can disrupt social

92 cohesion (Tuyttens et al. 2000). For wildlife species with more fluid group membership,

93 such as white-tailed deer (Odocoileus virginianus; Hawkins and Klimstra 1970, Nixon et

94 al. 1994, Comer et al. 2005), the task of understanding disease transmission may be greatly

95 complicated. Therefore, joint space use may not provide a reliable indicator of potential

96 contact between two animals when social group membership also has a large effect on

97 contact rates. Our objective was to assess the relative effects of joint space use and group

98 membership on pairwise direct and indirect contact rates among white-tailed deer.

99 Specifically, we sought to test whether elevated contact rates within social groups are

100 simply explained by their high degree of joint space use.

101 STUDY AREA

102 Our study took place approximately $4 \mathrm{~km}$ southeast of Carbondale, Illinois, USA

$103\left(37^{\circ} 42^{\prime} 14^{\prime \prime} \mathrm{N}, 89^{\circ} 9^{\prime} 2^{\prime \prime} \mathrm{E}\right)$, an area primarily in the Central Hill Plains ecological unit,

104 oak-hickory section (Keys, Jr. et al. 1995). The climate was characterized by relatively

105 short winters and hot, humid summers, with mean annual precipitation of $116.5 \mathrm{~cm}$, mean

106 January low temperature of $-6.2^{\circ} \mathrm{C}$, and mean July high temperature of $31^{\circ} \mathrm{C}$ (Midwestern

107 Regional Climate Center 2006). The study area consisted of relatively contiguous patches

108 of oak-hickory forest (57\%), hay fields and other grasslands (26\%), and row crop

109 agriculture (primarily soybeans, 12\%), with minor components of human habitation and

110 old fields. 


\section{METHODS}

\section{Capture and Collaring}

113 We focused on capturing adult and yearling females, although we also captured and 114 monitored some fawns and males. We captured most deer at sites baited with corn and 115 apples by using dart projectors (Pneu-Dart, Inc., Williamsport, Pennsylvania, USA) to fire

$1163-\mathrm{cc}$ barbed darts containing a mixture of Telazol $\mathrm{HCl}(4 \mathrm{mg} / \mathrm{kg})$ and xylazine $\mathrm{HCl}(2$ $117 \mathrm{mg} / \mathrm{kg}$ ), based on a 50-kg deer (Kilpatrick and Spohr 1999). Each dart contained a radio 118 transmitter for locating immobilized animals. We also used rocket-propelled or drop nets 119 at baited sites, and we immobilized deer captured in nets with an intramuscular injection of

$12010 \mathrm{mg} / \mathrm{kg}$ ketamine $\mathrm{HCl}$. We blindfolded all deer during handling; aged them by tooth 121 eruption as fawn, yearling, or adult; sexed; and fitted them with a GPS collar. The

122 Southern Illinois University Carbondale Institutional Animal Care and Use Committee 123 (protocol \#03-003) approved deer capture and handling methods.

We fitted deer with GPS collars (Model TGW-3500, weight 700 g; Telonics, Mesa,

125 Arizona, USA) that stored location data internally. Pilot data ( $n=1214$ locations) from

126 these collars at fixed locations under closed-canopy conditions indicated a median position

127 error of $8.8 \mathrm{~m}$ and a 95th percentile error of $30 \mathrm{~m}$. Pre-programmed release mechanisms 128 caused the collars to drop off the deer at particular times and dates. Collars deployed in

1292002 and 2003 recorded locations hourly and we programmed them to drop off after 4-5.5

130 months. Collars deployed in January-February 2004 recorded locations at 2-hour intervals

131 until January 2005, during November and December 2004 when they recorded locations

132 hourly. We set fix timeout at $3 \mathrm{~min}$, so all collars achieving fixes at a given hour 
133 (concurrent fixes) did so $\leq 3 \mathrm{~min}$ of one another. We checked data from each animal for

134 errors, and excluded locations from analyses if the estimated elevation was $>100 \mathrm{~m}$

135 different from the typical elevation on the study area (ca. $100 \mathrm{~m}$ ). We also excluded all

136 data from the first $3 \mathrm{~d}$ after collaring to avoid including aberrant behaviors resulting from

137 capture and immobilization.

\section{Joint Space Use and Group Membership}

139 Adult does nearing parturition (which begins ca. 1 June in southern Illinois, Rohm

$1402005)$ sequester themselves from their family groups and maintain small, exclusive

141 territories for 1-2 mo (Nixon et al. 1992, Bertrand et al. 1996). Because we expected

142 contacts to be less frequent during this period, we calculated contact rates and joint space

143 use separately for summer (15 May to $31 \mathrm{Aug}$ ) and fall-spring (1 Sep to 14 May) periods.

144 We measured joint space use by the volume of intersection of utilization

145 distributions (VI; Millspaugh et al. 2004), which takes values ranging from 0 (no joint

146 space use) to 1 (perfect concordance of utilization distributions). For each seasonal period,

147 we estimated home range of each deer from 200 randomly selected locations (Seaman et

148 al. 1999, Girard et al. 2002). We applied a fixed kernel estimator, with smoothing

149 parameter determined by least-squares cross-validation (Seaman and Powell 1996). We

150 then calculated VI for each pair of deer by calculating the approximate spatial integral of

151 the square root of the product of their kernels, following the raster approach of Millspaugh

152 et al. (2004). To assess the repeatability of VI calculations, we selected 1 pair of deer from

153 each of 5 seasonal time periods (Fall-Spring 2002-2003, Summer 2003, Fall-Spring

154 2003-2004, Summer 2004, Fall-Spring 2004-2005) with mid-range VI values (0.25 to 0.75, 
155 where variance should be maximal), and calculated the standard deviation of 10 replicate

156 VI values from separate random samples of 200 locations from each of those deer and 157 seasons.

158 We identified pairs of deer in the same social groups based on both high levels of 159 joint space use and highly correlated movements. Location is a multivariate quantity (x, $\mathrm{y}$ 160 coordinates), so Ramsey et al. (2002) used canonical correlation analysis to measure the 161 correlation of a linear combination of $\mathrm{x}$ and $\mathrm{y}$ between animals. However, spatial

162 coordinates are inherently orthogonal and measured on the same scale for all animals, so 163 we simply took the sum of the universal transverse mercator (UTM) x- (easting) and y-

164 (northing) coordinates for each location of each deer and calculated the univariate 165 correlation (Pearson's $r$ ) between the coordinate sums for each pair of deer with $>100$ 166 concurrent locations ( $n=115$ pairs). After identifying social groups based on outlying 167 correlation coefficients $(r \geq 0.5)$, we then compared direct and indirect contact rates within 168 versus between groups as a function of VI. If contact rates are especially high within

169 social groups, we predicted that within-group pairs would exhibit higher contact rates than 170 predicted based on VI alone.

\section{Calculating Contact Rates}

172 We based our analysis of direct contact rate on the assumptions that the frequency

173 at which 2 animals come close enough that their GPS-estimated locations are within a

174 critical distance $(\delta)$ from one another is a positive predictor of the probability of direct

175 transmission of a disease between them, and that smaller values of $\delta$ are likely to provide 176 stronger predictors. Thus, our unit of study was the deer pair (deer $i$ and $j$ ), for which we 
177 defined a direct contact as occurring when their concurrent (at time $t$ ) GPS-estimated

178 locations were $<\delta \mathrm{m}$ apart. Because GPS locations are not perfectly precise in space or

179 time, we quantified direct contact rates for a range of $\delta(10,25,50$, and $100 \mathrm{~m})$. Direct

180 contact rate for a deer pair in a given season was simply the proportion of concurrent

181 location pairs in that season that constituted contacts (contingent on $\delta$ ). Similarly, we

182 defined an indirect contact as occurring when the GPS location of donor deer $i$ at time $t$

183 and a subsequent (at time $t+\Delta t$ ) GPS location of a recipient deer $j$ were $<\delta \mathrm{m}$ apart, and

184 indirect contact rate was the proportion of lagged donor-recipient location pairs (contingent

185 on $\Delta t$ ) that constituted contacts. We based this approach on the assumption that the

186 probability of disease transmission via environmental contamination has a positive

187 relationship with the frequency at which a recipient animal comes near a site previously

188 occupied by a donor animal. We used the same set of $\delta$ for indirect as for direct contacts

189 and a range of time lags $(\Delta t=1,3,10$, and $30 \mathrm{~d})$. Note that a direct contact is equivalent to

190 an indirect contact with $\Delta t=0$. At a given value of $\Delta t$, we excluded pairs of deer from

191 analysis if <100 pairs of valid locations were available.

\section{Statistical Analysis}

193 By definition, members of a social group are not independent in their interactions

194 with other individuals. Therefore, we retained only 1 randomly selected deer from each

195 social group for analysis of between-group contact rates. Similarly, indirect contact rates

196 with each deer in a pair as donor (i.e., with deer $i$ as donor and deer $j$ as recipient, and vice

197 versa) are not independent of each other, so we randomly selected 1 for inclusion. 
Our objectives were to quantify the relationship between probability of contact

199 (direct or indirect) for a deer pair and their level of joint space use, and to test whether

200 within-group pairs exhibited higher contact rates than expected on the basis of joint space

201 use alone. Our data for each deer pair $(i)$, proximity criterion $(\delta)$, and time lag $(\Delta t)$

202 consisted of a time series of $1 \mathrm{~s}$ and 0 s indicating whether each location pair at time $t$ met

203 the criterion of a contact. We expected contact rates to differ among pairs of deer and

204 times. To account for time effects, we classified each record (pair of locations for deer pair

$205 i$ at time $t$ ) into a time period (Fall-Spring 2002-2003, Summer 2003, Fall-Spring 2003-

206 2004, Summer 2004, or Fall-Spring 2004-2005). The time periods were themselves

207 classified into seasons: summer vs. fall-spring, as we expected the rates of contact to be

208 generally different between summer and fall-spring. Within a time period, we assumed

209 that contact rate was constant (after accounting for other effects), except that we expected

210 first-order autocorrelation in contact probability (i.e., elevated probability of contact for

211 deer pair $i$ at time $t$ if the pair was in contact at time $t-1$ or $t-2 \mathrm{hrs}$ ). We assumed that any

212 other variation in contact rate among time periods having accounted for season can be

213 modeled using a normal distribution (i.e., period has a random effect whereas season has a

214 fixed effect).

215 We expected that the contact probability of each deer pair would have a positive

216 (and perhaps nonlinear) relationship with their level of joint space use (VI). In addition,

217 we sought to test whether pair type (i.e., whether the 2 deer were in the same vs. different

218 social groups) could explain additional among-pair variation in contact probability. We

219 assumed that any additional variation among deer pairs after accounting for VI and pair 
220 type could be modeled by a normal distribution (i.e., deer pair has a random effect whereas

221 pair type has a fixed effect). We considered measurement errors in VI to be negligible (see

222 Results: Space Use), so we did not use an errors-in-variables approach.

We conducted this analysis using mixed-model logistic regression (SAS Macro

224 Glimmix; Littell et al. 1996). For each value of $\delta$ and $\Delta t$, and using $i$ to index deer pair $(i=$

2251 to 115 ) and $t$ to index the time of the donor location ( $t=1$ to $19,271 \mathrm{hrs}$ ), we modeled

226 contact probability using the following response and explanatory variables (Table 1):

$227 \operatorname{logit}\left(\pi_{i t}\right)=$

228

$\beta_{0}+\beta_{1} V_{i, s(t)}+\beta_{2} V_{i, s(t)}^{2}+\left(\beta_{3} S(t)+e_{s(t)}\right)+\beta_{4} Y_{i, t-1}+\beta_{5} S(t) Y_{i, t-1}+\left(\beta_{6} P_{i}+\beta_{7} S(t) P_{i}+e_{i}\right)$

229 To directly estimate seasonal odds ratios of within- vs. between-group contact, with

230 associated confidence intervals, we also fitted the following equivalent model:

$231 \operatorname{logit}\left(\pi_{i t}\right)=$

$232 \beta_{0}+\beta_{1} V_{i, s(t)}+\beta_{2} V_{i, s(t)}^{2}+\left(\beta_{3} S(t)+e_{s(t)}\right)+\beta_{4} Y_{i, t-1}+\beta_{5} S(t) Y_{i, t-1}+\left(\beta_{6}(1-S(t)) P_{i}+\beta_{8} S(t) P_{i}+e_{i}\right)$

234 where $\beta_{6}$ is the effect of being a within-group pair (after accounting for other variables) on

235 the log-odds of contact in summer and $\beta_{8}$ is the pair type effect in fall-spring.

\section{RESULTS}

\section{Collar Performance}

We used GPS collars to monitor 20 females (2 fawns, 4 yearlings, and 14 adults)

239 and 3 males (1 fawn, 1 yearling, 1 adult) between October 2002 and January 2005. Each

240 collar collected between 235 and 10,493 valid locations over periods ranging from 2 weeks

241 to $>14$ months before it dropped off or the animal was killed (Fig. 1). Monthly mean fix 
242 success was $>98 \%$ during winter and ranged from $92-95 \%$ during late spring and summer.

243 Minimum monthly mean fix success among collars was $81 \%$. Collars deployed in

244 January-February 2004 exhibited a greater mean frequency of high-precision (position

245 dilution of precision $<5)$ fixes $(73 \%$ in summer, $82 \%$ in winter) than collars deployed at

246 other times (55\% in summer, $62 \%$ in winter), even during concurrent periods, perhaps due

247 to updated hardware or software in the collars. There were only 28 suspect locations due

248 to anomalous altitude, with a maximum of 8 such suspect locations for an individual

249 animal. Median time to fix ranged among collars from 38 to $66 \mathrm{sec}$, and the central span

250 (5th to 95th percentile) of time to fix for all collars was 15 to 149 sec.

251 Space Use

Among females for which we were able to estimate home range for both fall-spring

253 and summer seasons $(n=11)$, mean $( \pm$ SE) home range size was $105 \pm 13$ ha in fall-spring

254 and $45 \pm 4$ ha in summer. Deer 19, an adult female, had 2 separate home ranges with

255 centers ca. $1 \mathrm{~km}$ apart, which it switched between at 1- to 3-month intervals. All other

256 females made $\geq 1$ distinct excursion outside their home ranges during the monitoring

257 period, but did not establish new home ranges. These excursions typically lasted $<1 \mathrm{~d}$, and

258 straight-line distance from the home-range centroid to the furthest excursion point ranged

259 from 1.0 to $7.9 \mathrm{~km}$ (median $=2.7 \mathrm{~km})$. Replicate VI values for deer pairs with mid-range

260 VI had SD ranging from 0.025 to 0.055 (median $\mathrm{SD}=0.031$ ), which is quite small relative

261 to the range of VI among pairs (0 to 0.8 ). 
262

263

264

265

\section{Group Membership}

Mean $( \pm$ SE) pairwise correlation of movement was $0.033 \pm 0.014$. We identified 3 within-group pairs based on extensive home-range overlap (VI > 0.6) and highly correlated movements $(r \geq 0.5, Z \geq 3.2)$. Deer 8 and 9 were fawns (male and female) collared simultaneously in March 2003, which we presumed to be siblings. The other 2 within-group pairs were composed of females, either adult-adult (deer 16 and 17) or adult-yearling (deer 21 and 22). Another pair of adult females (deer 18 and 19) did not exhibit characteristics of a social group during spring 2004, but did in fall 2004 during periods when deer 19 inhabited its southwestern home range. Therefore, we treated this pair as a between-group pair until fall 2004, and as a within-group pair thereafter. In general, VI was lower for between- than within-group pairs, but 7 between-group pairs had VI $>0.7$ and 2 within-group pairs had VI $<0.7$

\section{Direct Contact Rates}

Across a range of proximity criteria $(\delta=10$ to $100 \mathrm{~m})$, the log-odds of direct contact showed strong, but nonlinear, positive relationships with VI (Fig 2A, Fig. 3A-B), with direct contact rates very close to zero for $\mathrm{VI}<0.5$. Direct contact rates were lower in summer than in fall-spring and showed strong temporal autocorrelation (Fig. 2B).

Within-group direct contact rates were significantly greater than expected based on season and VI alone (Fig. 3A-B), and the pair-type $\times$ season interaction was significant for all values of $\delta$ (Fig. 2B). The effect of group membership was much greater in fall-spring than in summer. Based on logistic regression coefficients, the odds of direct contact during fall-spring were 22.1-fold greater for within-group than between-group pairs at $\delta=$ 
$28410 \mathrm{~m}$ after accounting for VI, and this odds ratio declined to 5.0 but remained significantly

$285>1$ out to $\delta=100 \mathrm{~m}$ (Fig. 4A). In contrast, within:between-group odds ratios for direct

286 contacts during summer had $95 \%$ CIs that included 1 for all values of $\delta$ (Fig. 4A).

287 Qualitative patterns emerging from analysis of direct contact rates were generally

288 unaffected by the value of $\delta$, although temporal autocorrelation generally increased and

289 pair type effects became smaller with increasing $\delta$ (Fig. 2A-B).

\section{Indirect Contact Rates}

As with direct contact rates, the log-odds of indirect contact increased significantly,

292 but nonlinearly, with VI and showed strong temporal autocorrelation with little qualitative

293 or quantitative change in these relationships as $\Delta t$ ranged from 1 to $30 \mathrm{~d}$ (Fig. 2C-J, Fig.

294 3C-F). The relationship between indirect contact rates and VI was more variable than for

295 direct contact rates, with some between-group pairs with VI > 0.6 having similar indirect

296 contact rates to pairs with VI $~ 0.3$ (Fig. 3C-F). In general, coefficients related to pair-type

297 effects on indirect contact rates were much smaller in magnitude than was the case for

298 direct contacts, although point estimates of the pair-type main effect on indirect contacts

299 tended to be positive (Fig. 2C-J). Effects of pair type on indirect contacts were only

300 evident at $\delta=10$ with $\Delta t=1$ and $\Delta t=10$ (Fig. 2D-J); otherwise, estimated within:between-

301 group odds ratios for indirect contacts during fall-spring were generally close to and not

302 significantly different from 1 , except for $\delta=10$ with $\Delta t=1$ and $\Delta t=10$ (Fig. 4B-C). For

303 indirect contacts in summer, estimated within:between-group odds ratios did not differ

304 significantly from 1 for any value of $\delta$ or $\Delta t$, although they were sometimes extremely

305 imprecise (Fig. 4B-C). At a given value of $\delta$, logistic regression coefficients differed little 
306 as $\Delta t$ varied from 1 to $30 \mathrm{~d}$ (Fig. $2 \mathrm{C}-\mathrm{J})$, and this robustness to variations in $\Delta t$ was apparent

307 in the relationship between indirect contact rates and VI (Fig. 3C-F).

\section{DISCUSSION}

309 In analyzing contacts rates measured from GPS-collared white-tailed deer, our

310 primary finding is that joint space use alone does not appear to be a reliable indicator of

311 either group membership or likely levels of direct contact among white-tailed deer. Some

312 pairs of deer had high levels of overlap in their utilization distributions without their

313 movements being strongly correlated, indicating that they were not acting as a social

314 group. Even after accounting for the fact that within-group pairs had high VI, the odds of

315 direct contact with $\delta=10 \mathrm{~m}$ were ca. 20 times greater for within- than between-group

316 pairs. The large discrepancy in direct contact rates between within- and between-group

317 pairs of white-tailed deer suggests that directly transmitted diseases should spread much

318 more rapidly within than between deer social groups. Thus, realistic models of disease

319 transmission should treat intra- and inter-group transmission differently. However, in

320 areas where deer social groups are stable and few females move between groups, the

321 discrepancy in contacts implies that managers could simplify models of disease spread by

322 treating groups as individuals and focusing on inter-group transmission. After all, if a

323 disease infects all members of 1 group, but is unable to spread to another group, that

324 epizootic fails as surely as if only 1 individual had become infected. We found that

325 between-group direct contacts had a strong relationship with VI, suggesting that joint space

326 use by different deer groups could be a valid indicator of inter-group direct contact, as

327 assumed by Conner and Miller (2004). 
We measured indirect contact rates among deer using a range of proximity criteria

329 and time lags separating donor and recipient locations. As with direct contacts, indirect

330 contact rates increased with increasing joint space use. However, the effect of group

331 membership after accounting for joint space use was much smaller and less consistent for

332 indirect than direct contacts, even for time lags as short as $1 \mathrm{~d}$. Therefore, differences in

333 indirect contacts between within- and between-group pairs of white-tailed deer appear to

334 be driven primarily by the high level of joint space use between members of the same

335 group. Variations in the time lag between donor and recipient visits of the same location

$336 \geq 1 \mathrm{~d}$ had little effect. This implies that the effects of joint space use and group

337 membership on indirect contact rates among white-tailed deer are relatively robust to

338 variations in the expected persistence of pathogens. Of course, the probability of indirect

339 transmission is likely to increase if pathogens persist longer, but our point is that the

340 qualitative pattern of indirect contacts relative to joint space use and group membership

341 may be relatively unaffected by the duration of pathogen persistence.

342 Relative to direct contacts, indirect contacts showed greater variability around the

343 relationship with VI. This variability may reflect the importance of excursions outside the

344 home range. Based on average home range size for deer in our study, the median

345 excursion distance of $2.7 \mathrm{~km}$ represents a trek equivalent to nearly 5 home-range radii. A

346 deer that temporarily travels outside its home range into unfamiliar territory may avoid

347 direct, and potentially aggressive, contact with resident deer. However, persistent

348 pathogens left behind could substantially accelerate the spread of disease among social

349 groups. Rare, long-distance movements are particularly important in the spread of 
350 invading populations (Kot et al. 1996) and gene flow (Nelson 1993). Thus, temporary

351 excursions could play a disproportionate role in geographic spread of diseases in

352 white-tailed deer, especially diseases like CWD that are more prevalent among adults than

353 among yearlings (Miller et al. 2000, Gross and Miller 2001, Williams et al. 2002, Joly et

354 al. 2003), the primary age-class of dispersers (Hawkins et al. 1971, Kammermeyer and

355 Marchinton 1976, Nelson and Mech 1992, Nixon et al. 1994).

356 Our results have bearing on the debate over whether disease transmission among

357 wildlife is best characterized as density-dependent or frequency-dependent (de Jong et al.

358 1995, McCallum et al. 2001, de Jong et al. 2002, McCallum et al. 2002, Schauber and

359 Woolf 2003). Density-dependent transmission implies that force of infection drops as host

360 population decreases, allowing the population to rebound and potentially resulting in

361 population stability (Anderson and May 1978). If transmission is strictly

362 frequency-dependent, however, force of infection stays high even as the population crashes

363 (Getz and Pickering 1983). Researchers have proposed transmission within social groups

364 as a mechanism for frequency-dependent transmission (Altizer et al. 2003) because

365 animals within a social group make frequent contacts regardless of the density of the

366 surrounding population. However, within-group contacts alone cannot perpetuate an

367 epizootic, so between-group transmission is critical to the impact on host persistence.

368 Some researchers have found that group size in deer increases only weakly with population

369 density (Thirgood 1996, Shankar Raman 1997, Borkowski 2000), supporting the

370 hypothesis that direct transmission within social groups is largely frequency-dependent.

371 However, if group size is relatively constant, then population density must be largely 
372 determined by the number of social groups per unit area. Thus, overall direct contact rate

373 between one group and all neighboring groups is likely to increase with population density.

374 Our finding that indirect contact rates are similar within and between groups suggest that

375 transmission of persistent pathogens via environmental contamination is very likely to be

376 density dependent. However, high pathogen persistence is likely to produce delayed

377 density dependence, which can increase the amplitude of disease-driven fluctuations in

378 host abundance (May and Anderson 1978).

\section{Caveats}

380 Our results suffer from a number of weaknesses, which future research in this area

381 should consider. Foremost, we analyzed contacts between particular pairs of deer, but 382 spread of disease is controlled by the total contact rate between each individual and all

383 other individuals (Dietz 1982). GPS collars are costly, so researchers can generally only

384 use them to monitor a subset of a population. Thus, scaling up from pairwise to total

385 contact rates requires at a minimum knowing the number of groups inhabiting an area,

386 typical group sizes, and levels of joint space use among groups. These factors are all likely

387 to vary with population density and landscape configuration, and thus represent the

388 mechanistic link between such ecological factors and effects on epizootiology.

389 Our measurements of contact rates are imperfect measurements of true contact

390 probabilities, which are imperfect measurements of the probability of transmission of

391 particular pathogens. The ideal proximity criterion $(\delta)$ to indicate contact would be zero,

392 but limits of precision of GPS-derived locations in space and time set a lower bound on

393 meaningful values of $\delta$. However, the within:between odds-ratio of direct contact rates 
394 was greatest for a proximity criterion of $10 \mathrm{~m}$, so $10 \mathrm{~m}$ appears to be a suitable criterion for

395 defining direct contacts from GPS collar data. In our pilot data (described in Methods),

396 location errors typically caused observed distances between nearby GPS collars to exceed

397 the true distance, so the observed frequency of contacts based on GPS locations apart

398 almost certainly underestimates the true frequency. Simulations indicate that the relative

399 magnitude of this bias increases as $\delta$ decreases, and the true contact rate increases (E.

400 Schauber, Southern Illinois University Carbondale, unpublished data). Therefore, the

401 effect of group membership on contact rates may be greater than we report here.

402 Our study focused mainly on adult females, so we were unable to examine

403 differences between inter- and intra-sex transmission. We studied contact between females

404 because: (1) few diseases of deer have been shown to be primarily spread to females from

405 males, (2) the female population controls population growth, and (3) collaring adult males

406 is problematic due to neck swelling during the rut. However, some diseases could be

407 spread by the act of copulation as well as sniffing and flehmening of urine and other

408 secretions during the mating season. For example, CWD tends to be much more prevalent

409 in adult male than female deer (Farnsworth et al. 2005), suggesting that males that attempt

410 to breed with large numbers of females may experience high levels of exposure.

411 Our statistical analyses rely on some assumptions that may be violated. We used

412 deer pairs rather than individual deer as the sampling units, but contact rates for deer pair

413 A-B may not be independent of those for deer pairs B-C or A-C. For example, deer B

414 might be more (or less) sociable than average, so its presence affects the contact rates of

415 pair $\mathrm{A}-\mathrm{B}$ and $\mathrm{B}-\mathrm{C}$ in the same direction. Thus, we based our analysis on the assumption 
416 that non-independence arises solely through group membership and joint space use, not

417 through behavioral characteristics of individual animals. Also, we assumed that missing

418 data are a random subset of all possible data for each deer pair and season. Fix success and 419 precision of GPS collars vary with animal behavior (e.g., bedded vs. standing), cover type,

420 topography, and season (Rempel et al. 1995, Moen et al. 1996, Dussault et al. 1999, D'Eon 421 et al. 2002, Di Orio et al. 2003). Thus, sites, times, and behaviors associated with low fix

422 success are likely to be underrepresented in data collected for a given individual, and could 423 bias estimates of contact rates. GPS collars generally had high fix success in our relatively 424 flat study area, but spatially varying fix success or precision could be a major consideration 425 when estimating contact rates in areas of more rugged terrain.

\section{MANAGEMENT IMPLICATIONS}

For directly transmitted diseases, our results indicate that managers should not 428 assume that measurements of joint space use (home range overlap or VI) among animals 429 provide reliable information about contact rates; the composition and size of social groups 430 also need to be known in order to make inferences about the potential direct transmission 431 of disease. Because we found a strong effect of group membership on direct contact rates, 432 we suggest that disease management by lethal population control could reduce the ability 433 of directly transmitted diseases to become established or persist in deer groups (due to 434 reduced group size and cohesion), but simultaneously increase the opportunity for an 435 already-established disease to spread among groups (due to reduced social cohesion). For 436 indirectly transmitted, diseases, on the other hand, our results indicate that joint space use 437 is a reliable indicator of potential contact rate among white-tailed deer, even if pathogens 
438 only persist for as short as $1 \mathrm{~d}$. Researchers commonly report home range overlap or VI in

439 field studies of deer, so data required for management decisions regarding indirectly

440 transmitted diseases may be readily available from published literature or acquired at lower

441 expense than is necessary for studies involving GPS collars.

\section{ACKNOWLEDGMENTS}

443 Constructive criticism from R. Barker, 2 anonymous reviewers, and M. Eichholz greatly

444 improved this manuscript. We thank C. and M. Bloomquist, V. Carter, L. J. Kjær, P.

445 McDonald, A. Nollman, J. Rohm, and J. Waddell for field assistance. We are indebted to

446 J. McDonald for initiating this project. We also thank the staff and graduate students of

447 the SIUC Cooperative Wildlife Research Laboratory for volunteering. Federal Aid in

448 Wildlife Restoration Project W-87-R, with additional support from the SIUC Graduate

449 School provided primary funding for this research. The late A. Woolf served as principal

450 investigator of this project until his death in April 2004. 
453

454

455

456

457

458

459

460

461

462

463

464

465

466

467

468

469

470

471

472

473

\section{LITERATURE CITED}

Altizer, S., C. L. Nunn, P. H. Thrall, J. L. Gittleman, J. Antonovics, A. A. Cunningham, A. P. Dobson, V. Ezenwa, K. E. Jones, A. B. Pedersen, M. Poss, and J. R. C. Pulliam. 2003. Social organization and parasite risk in mammals. Annual Review of Ecology, Evolution, and Systematics 34:517-547.

Anderson, R. M., and R. M. May. 1978. Regulation and stability of host-parasite population interactions: I. Regulatory processes. Journal of Animal Ecology $47: 219-247$.

Anderson, R. M., and R. M. May. 1986. The invasion, persistence and spread of infectious diseases within animal and plant communities. Philosophical Transactions of the Royal Society of London, Series B, Biological Sciences 314:513-570.

Bertrand, M. R., A. J. DeNicola, S. R. Beissinger, and R. K. Swihart. 1996. Effects of parturition on home ranges and social affiliations of female white-tailed deer. Journal of Wildlife Management 60:899-909.

Borkowski, J. 2000. Influence of the density of a sika deer population on activity, habitat use, and group size. Canadian Journal of Zoology 78:1369-1374.

Caley, P., N. Spencer, R. A. Cole, and M. Efford. 1998. The effect of manipulating population density on the probability of den-sharing among common brushtail possums and the implications for transmission of bovine tuberculosis. Wildlife Research 25:383-392. 
474 Cheeseman, C. L., W. J. Cresswell, S. Harris, and P. J. Mallinson. 1988a. Comparison of 475 dispersal and other movements in 2 badger (Meles meles) populations. Mammal $476 \quad$ Review 18:51-59.

477 Cheeseman, C. L., J. W. Wilesmith, F. A. Stuart, and P. J. Mallinson. 1988b. Dynamics of 478 tuberculosis in a naturally infected badger population. Mammal Review 18:61-72.

479 Comer, C. E., J. C. Kilgo, G. J. D'Angelo, T. C. Glenn, and K. V. Miller. 2005. Fine-scale 480 genetic structure and social organization in female white-tailed deer. Journal of

482 Conner, M. M., and M. W. Miller. 2004. Movement patterns and spatial epidemiology of a 483 prion disease in mule deer population units. Ecological Applications 14:1870-1881.

484 D'Eon, R. G., R. Serrouya, G. Smith, and C. O. Kochanny. 2002. GPS radiotelemetry error 485 and bias in mountainous terrain. Wildlife Society Bulletin 30:430-439.

486 de Jong, M. C. M., O. Diekmann, and H. Heesterbeek. 1995. How does transmission of 487 infection depend on population size? Pages 84-94 in D. Mollison, editors. Epidemic models: their structure and relation to data. Cambridge University Press, Cambridge, United Kingdom.

de Jong, M. C. M., A. Bouma, O. Diekmann, and H. Heesterbeek. 2002. Modelling transmission: mass action and beyond. Trends In Ecology and Evolution 17:64.

492 Di Orio, A. P., R. Callas, and R. J. Schaefer. 2003. Performance of two GPS telemetry 493 collars under different habitat conditions. Wildlife Society Bulletin 31:372-379. 
494 Dietz, K. 1982. Overall population patterns in the transmission cycle of infectious disease 495 agents. Pages 87-102 in R. M. Anderson and R. M. May, editors. Population biology of infectious diseases. Springer-Verlag, Berlin, Germany.

Dussault, C., R. Courtois, J. P. Ouellet, and J. Huot. 1999. Evaluation of GPS telemetry collar performance for habitat studies in the boreal forest. Wildlife Society Bulletin 27:965-972.

500 Farnsworth, M. L., L. L. Wolfe, N. T. Hobbs, K. P. Burnham, E. S. Williams, D. M. Theobald, M. M. Conner, and M. W. Miller. 2005. Human land use influences chronic wasting disease prevalence in mule deer. Ecological Applications 15:119-126.

Getz, W. M., and J. Pickering. 1983. Epidemic models: thresholds and population 505 regulation. American Naturalist 121:892-898.

506 Girard, I., J. P. Ouellet, R. Courtois, C. Dussault, and L. Breton. 2002. Effects of sampling 507 effort based on GPS telemetry on home-range size estimations. Journal of Wildlife Management 66:1290-1300.

509 Gross, J. E., and M. W. Miller. 2001. Chronic wasting disease in mule deer: disease 510 dynamics and control. Journal of Wildlife Management 65:205-215.

511 Hawkins, R. E., and W. D. Klimstra. 1970. A preliminary study of the social organization 512 of the white-tailed deer. Journal of Wildlife Management 34:407-419.

513 Hawkins, R. E., W. D. Klimstra, and D. C. Autry. 1971. Dispersal of deer from Crab 514 Orchard National Wildlife Refuge. Journal of Wildlife Management 35:216-220. 
515 Ji, W., P. C. L. White, and M. N. Clout. 2005. Contact rates between possums revealed by proximity data loggers. Journal of Applied Ecology 42:595-604.

517 Joly, D. O., C. A. Ribic, J. A. Langenberg, K. Beheler, C. A. Batha, B. J. Dhuey, R. E. 518 Rolley, G. Bartelt, T. R. Van Deelen, and M. D. Samuel. 2003. Chronic wasting 519 disease in free-ranging Wisconsin white-tailed deer. Emerging Infectious Diseases $520 \quad 9: 599-601$.

521 Kammermeyer, K. E., and R. L. Marchinton. 1976. Notes on dispersal of male white-tailed 522 deer. Journal of Mammalogy 57:776-778.

Keys, J., Jr., C. Carpenter, S. Hooks, F. Koenig, W. H. McNab, W. Russell, and M. L. Smith. 1995. Ecological units of the eastern United States. U.S. Department of Agriculture, Forest Service, Atlanta, Georgia, USA.

Kilpatrick, H. J., and S. M. Spohr. 1999. Telazol (R)-xylazine versus ketamine-xylazine: a field evaluation for immobilizing white-tailed deer. Wildlife Society Bulletin 27:566-570.

Kilpatrick, H. J., S. M. Spohr, and K. K. Lima. 2001. Effects of population reduction on home ranges of female white- tailed deer at high densities. Canadian Journal of Zoology 79:949-954.

532 Kot, M., M. A. Lewis, and P. van den Driessche. 1996. Dispersal data and the spread of invading organisms. Ecology 77:2027-2042.

534 Littell, R. C., G. Milliken, W. W. Stroup, and R. D. Wolfinger. 1996. SAS system for mixed models. SAS Institute, Inc., Cary, North Carolina, USA. 
536 Lugton, I. W., P. R. Wilson, R. S. Morris, and G. Nugent. 1998. Epidemiology and pathogenesis of Mycobacterium bovis infection of red deer (Cervus elaphus) in New Zealand. New Zealand Veterinary Journal 46:147-156.

May, R. M., and R. M. Anderson. 1978. Regulation and stability of host-parasite population interactions: II. Destabilizing processes. Journal of Animal Ecology 47:249-267.

McCallum, H., N. Barlow, and J. Hone. 2001. How should pathogen transmission be modelled? Trends in Ecology and Evolution 16:295-300.

McCallum, H., N. Barlow, and J. Hone. 2002. Modelling transmission: mass action and beyond. Trends In Ecology and Evolution 17:64-65.

McNulty, S. A., W. F. Porter, N. E. Mathews, and J. A. Hill. 1997. Localized management

Midwestern Regional Climate Center. 2006. Illinois climate summaries. for reducing white-tailed deer populations. Wildlife Society Bulletin 25:265-271. <http://mcc.sws.uiuc.edu/climate_midwest/maps/il_mapselector.htm>. Accessed

Miller, M. W., M. A. Wild, and E. S. Williams. 1998. Epidemiology of chronic wasting 23 Aug 2006. disease in captive Rocky Mountain elk. Journal of Wildlife Diseases 34:532-538.

Miller, M. W., and E. S. Williams. 2003. Horizontal prion transmission in mule deer.

555 Miller, M. W., E. S. Williams, N. T. Hobbs, and L. L. Wolfe. 2004. Environmental sources of prion transmission in mule deer. Emerging Infectious Diseases 10:10031006. 
558 Miller, M. W., E. S. Williams, C. W. McCarty, T. R. Spraker, T. J. Kreeger, C. T. Larsen, and E. T. Thorne. 2000. Epizootiology of chronic wasting disease in free-ranging cervids in Colorado and Wyoming. Journal of Wildlife Diseases 36:676-690.

561 Millspaugh, J. J., R. A. Gitzen, B. J. Kernohan, M. A. Larson, and C. L. Clay. 2004. Comparability of three analytical techniques to assess joint space use. Wildlife Society Bulletin 32:148-157.

Moen, R., J. Pastor, Y. Cohen, and C. C. Schwartz. 1996. Effects of moose movement and habitat use on GPS collar performance. Journal of Wildlife Management 60:659-668.

Nelson, M. E. 1993. Natal dispersal and gene flow in white-tailed deer in northeastern Minnesota. Journal of Mammalogy 74:316-322.

Nelson, M. E., and L. D. Mech. 1992. Dispersal in female white-tailed deer. Journal of Mammalogy 73:891-894.

Nelson, M. E., and L. D. Mech. 1999. Twenty-year home-range dynamics of a white-tailed deer matriline. Canadian Journal of Zoology 77:1128-1135.

Nixon, C. M., L. P. Hansen, P. A. Brewer, and J. E. Chelsvig. 1992. Stability of white-tailed doe parturition ranges on a refuge in east-central Illinois. Canadian Journal of Zoology 70:968-973.

576 Nixon, C. M., L. P. Hansen, P. A. Brewer, J. E. Chelsvig J. B. Sullivan, T. L. Esker, R. 577 Koerkenmeier, D. R. Etter, J. Cline, and J. A. Thomas. 1994. Behavior, dispersal, 578 and survival of male white-tailed deer in Illinois. Illinois Natural History Survey $579 \quad$ Biological Notes 139:1-29. 
O'Brien, D. J., S. M. Schmitt, J. S. Fierke, S. A. Hogle, S. R. Winterstein, T. M. Cooley, W. E. Moritz, K. L. Diegel, S. D. Fitzgerald, D. E. Berry, and J. B. Kaneene. 2002. Epidemiology of Mycobacterium bovis in free-ranging white-tailed deer, Michigan, USA, 1995-2000. Preventive Veterinary Medicine 54:47-63.

Palmer, M. V., W. R. Waters, and D. L. Whipple. 2004. Shared feed as a means of deer-todeer transmission of Mycobacterium bovis. Journal of Wildlife Diseases 40:87-91.

Porter, W. F., N. E. Mathews, H. B. Underwood, R. W. Sage, and D. F. Behrend. 1991. Social organization in deer: implications for localized management. Environmental Management 15:809-814.

Ramsey, D., N. Spencer, P. Caley, M. Efford, K. Hansen, M. Lam, and D. Cooper. 2002. The effects of reducing population density on contact rates between brushtail possums: implications for transmission of bovine tuberculosis. Journal of Applied Ecology 39:806-818.

Rempel, R. S., A. R. Rodgers, and K. F. Abraham. 1995. Performance of a GPS animal location system under boreal forest canopy. Journal of Wildlife Management $59: 543-551$.

Rohm, J. H. 2005. Survival of white-tailed deer fawns in southern Illinois. Thesis. Southern Illinois University, Carbondale, Illinois, USA.

Schauber, E. M. and A. Woolf. 2003. Chronic wasting disease in deer and elk: a critique of current models and their application. Wildlife Society Bulletin 31:610-616.

Seaman, D. E. and R. A. Powell. 1996. An evaluation of the accuracy of kernel density estimators for home range analysis. Ecology 77:2075-2085. 
602

603

604

605

606

607

608

609

610

611

612

613

614

615

616

617

618

619

620

621

622

Seaman, D. E., J. J. Millspaugh, B. J. Kernohan, G. C. Brundige, K. J. Raedeke, and R. A. Gitzen. 1999. Effects of sample size on kernel home range estimates. Journal of Wildlife Management 63:739-747.

Shankar Raman, T. R. 1997. Factors influencing seasonal and monthly changes in the group size of chital or axis deer in southern India. Journal of Biosciences 22:203-218.

Thirgood, S. J. 1996. Ecological factors influencing sexual segregation and group size in fallow deer (Dama dama). Journal of Zoology 239:783-797.

Totton, S. C., R. R. Tinline, R. C. Rosatte, and L. L. Bigler. 2002. Contact rates of raccoons (Procyon lotor) at a communal feeding site in rural eastern Ontario. Journal of Wildlife Diseases 38:313-319.

Tuyttens, F. A. M., R. J. Delahay, D. W. MacDonald, C. L. Cheeseman, B. Long, and C. A. Donnelly. 2000. Spatial perturbation caused by a badger (Meles meles) culling operation: implications for the function of territoriality and the control of bovine tuberculosis (Mycobacterium bovis). Journal of Animal Ecology 69:815-828.

Vincent, J. P., E. Bideau, A. J. M. Hewison, and J. M. Angibault. 1995. The influence of increasing density on body weight, kid production, home range and winter grouping in roe deer (Capreolus capreolus). Journal of Zoology 236:371-382.

White, P. C. L., and S. Harris. 1994. Encounters between red foxes (Vulpes vulpes): implications for territory maintenance, social cohesion and dispersal. Journal of Animal Ecology 63:315-327. 
623 White, P. C. L., G. A. Newton-Cross, M. Gray, R. Ashford, C. White, and G. Saunders. 624 2003. Spatial interactions and habitat use of rabbits on pasture and implications for 625 the spread of rabbit haemorrhagic disease in New South Wales. Wildlife Research 626 30:49-58.

627 Williams, E. S., M. W. Miller, T. J. Kreeger, R. H. Kahn, and E. T. Thorne. 2002. Chronic 628 wasting disease of deer and elk: a review with recommendations for management. 629 Journal of Wildlife Management 66:551-563.

630 Associate Editor: Barker

631 


\section{TABLES}

633 Table 1. Definitions of terms involved in the statistical modeling of contact rate among

634 white-tailed deer near Carbondale, Illinois, 2002-2005.

\begin{tabular}{|c|c|}
\hline Term & Definition \\
\hline $\operatorname{logit}\left(\pi_{i t}\right)$ & $\begin{array}{l}\text { The logit (log-odds) of contact probability, based on distance criterion }(\delta) \\
\text { and time lag }(\Delta t), \text { for deer pair } i \text { at time } t\end{array}$ \\
\hline$\beta_{0}$ & $\begin{array}{l}\text { Value of logit }\left(\pi_{i t}\right) \text { in fall-spring for deer in different groups if there was no } \\
\text { contact between the pair the previous time ( } 1 \text { or } 2 \text { hrs earlier) }\end{array}$ \\
\hline$\beta_{1}$ & Linear term of the relationship between $\operatorname{logit}\left(\pi_{i t}\right)$ and $V_{i, s(t)}$ \\
\hline$\beta_{2}$ & Quadratic term of the relationship between $\operatorname{logit}\left(\pi_{i t}\right)$ and $V_{i, s(t)}$ \\
\hline$\beta_{3}$ & Amount by which logit $\left(\pi_{i t}\right)$ is increased in summer \\
\hline$\beta_{4}$ & $\begin{array}{l}\text { Amount by which logit }\left(\pi_{i t}\right) \text { is increased in fall-spring if there was a contact } \\
\text { between the pair } i \text { at the previous time ( } 1 \text { or } 2 \text { hrs earlier) }\end{array}$ \\
\hline$\beta_{5}$ & Amount to add to $\beta_{3}$ to obtain the effect of previous contact in summer \\
\hline$\beta_{6}$ & $\begin{array}{l}\text { Amount by which logit }\left(\pi_{i t}\right) \text { is increased in fall-spring if the } 2 \text { deer are in the } \\
\text { same social group }\end{array}$ \\
\hline$\beta_{7}$ & Amount to add to $\beta_{6}$ to obtain the group effect in summer \\
\hline$s(t)$ & Time period (e.g., Fall-Spring 2002-2003) at time $t(s(t)=1$ to 5$)$ \\
\hline$S(t)$ & Indicator of season at time $t(S(t)=0$ if Fall-Spring, 1 if summer $)$ \\
\hline$V_{i, s(t)}$ & Volume of intersection of deer pair $i$ in time period $s(t)$ \\
\hline$Y_{i, t}$ & Indicator of contact for pair $i$ at time $t$ \\
\hline
\end{tabular}


$P_{i} \quad$ Pair type of deer pair $i\left(P_{i}=1\right.$ if members of the same social group, $P_{i}=0$ if members of different groups)

$e_{\mathrm{S}(t)} \quad$ Mean-zero independent normal random error for describing unexplained differences in $\operatorname{logit}\left(\pi_{i t}\right)$ among periods after accounting for season

$e_{i} \quad$ Mean-zero independent normal random error for describing unexplained differences in logit $\left(\pi_{i t}\right)$ among deer pairs after accounting for the combined effects of pair-type and season 


\section{FIGURE LEGENDS}

637 Figure 1. (A) Periods of monitoring and (B) number of valid locations for individual

638 white-tailed deer collared with GPS collars near Carbondale Illinois, 2002-2005. Deer

639 nos. 5, 7, and 8 (designated with "M") were fawn, yearling, and adult males, respectively.

640 Vertical lines in (A) delineate seasons for statistical analyses.

641

642 Figure 2. Estimated logistic regression coefficients $(\hat{\beta})$, with 95\% CIs, from model

643 fitting to contact rates between pairs of white-tailed deer near Carbondale, Illinois,

644 2002-2005. We included deer pair and period (e.g., Fall-Spring 2002-03) as random

645 effects. Different symbols indicate different distance criteria $(\delta)$ used to define contacts

646 (filled circle--10 m, open circle--25 m, filled triangle--50 m, open triangle--100 m). (A,

647 B) Direct contacts $(\Delta t=0),(\mathrm{C}, \mathrm{D})$ indirect contacts with $\Delta t=1 \mathrm{~d},(\mathrm{E}, \mathrm{F}) \Delta t=3 \mathrm{~d},(\mathrm{G}, \mathrm{H})$

$648 \Delta t=10 \mathrm{~d}$, (I, J) $\Delta t=30 \mathrm{~d}$. Note the different scale for the vertical axis of panel (H).

649 "Season" indicates the effect of summer, "Prev" indicates the effect of the pair of deer

650 being in contact 1 or $2 \mathrm{hrs}$ before, and "Pair-type" indicates the effect of both members of

651 the pair being members of the same social group. Positive coefficients imply positive

652 effects on contact rates. Vertical lines spanning a panel indicate extremely imprecise

653 coefficient estimates (CIs extend beyond \pm 240 ).

654

655 Figure 3. Relationship between seasonal contact rates and joint space use (volume of 656 intersection) for between-group (filled symbols) and within-group (open symbols) pairs 657 of white-tailed deer near Carbondale, Illinois, 2002-2005. Proximity criteria $(\delta)$ defining 
658 contacts were (A,C,E) $10 \mathrm{~m}$ and $(\mathrm{B}, \mathrm{D}, \mathrm{F}) 100 \mathrm{~m}$. (A-B) Direct contacts $(\Delta t=0),(\mathrm{C}-\mathrm{D})$

659 indirect contacts with $\Delta t=1 \mathrm{~d},(\mathrm{E}-\mathrm{F})$ indirect contacts with $\Delta t=30 \mathrm{~d}$.

660

661 Figure 4. Estimated odds ratio of within- versus between-group contact rates for

662 white-tailed deer near Carbondale, Illinois, 2002-2005, as a function of the proximity

663 criterion and season (filled symbols for fall-spring, open symbols for summer). Error

664 bars indicate $95 \%$ CI for estimated odds ratio from mixed-model logistic regression. (A)

665 Direct contacts, (B) indirect contacts with $\Delta t=1$ or $3 \mathrm{~d},(\mathrm{C})$ indirect contacts with $\Delta t=10$

666 or $30 \mathrm{~d}$. Proximity criteria in (B) and (C) are offset by $\pm 1.5 \mathrm{~m}$ to avoid overlapping

667 symbols for different values of $\Delta t$. CIs for summer odds ratios extending outside of

668 graphs (B) and (C) extend from $<10^{-80}$ to $>10^{90}$.

669

670 


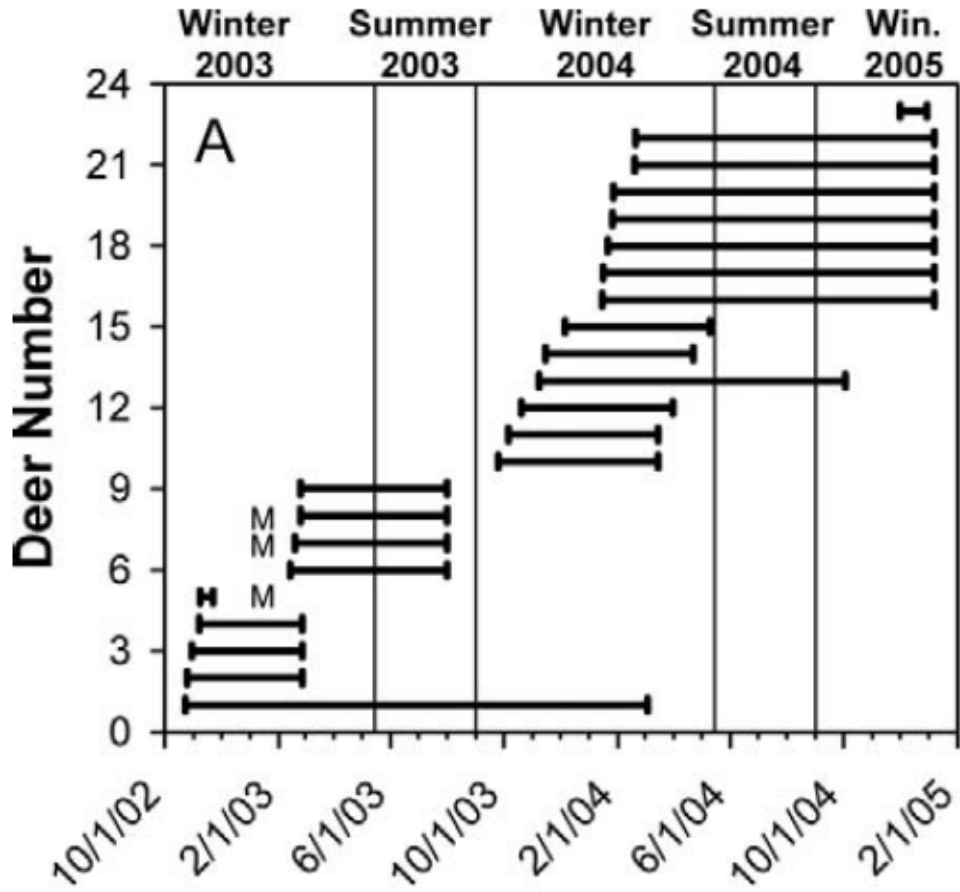

Date
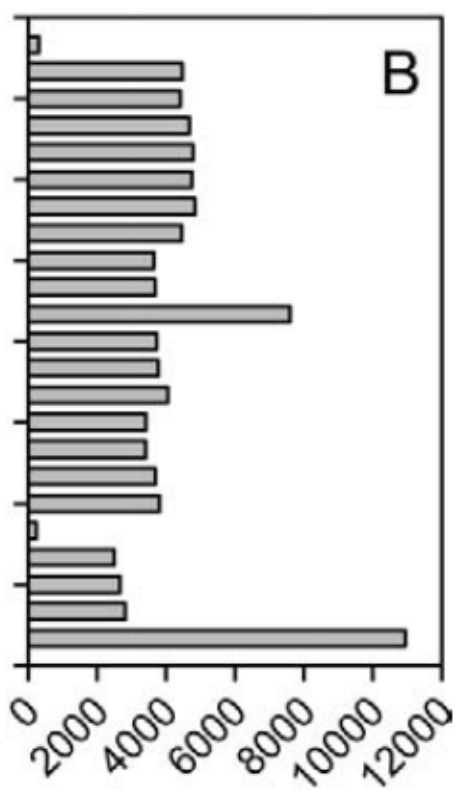

Locations

672 


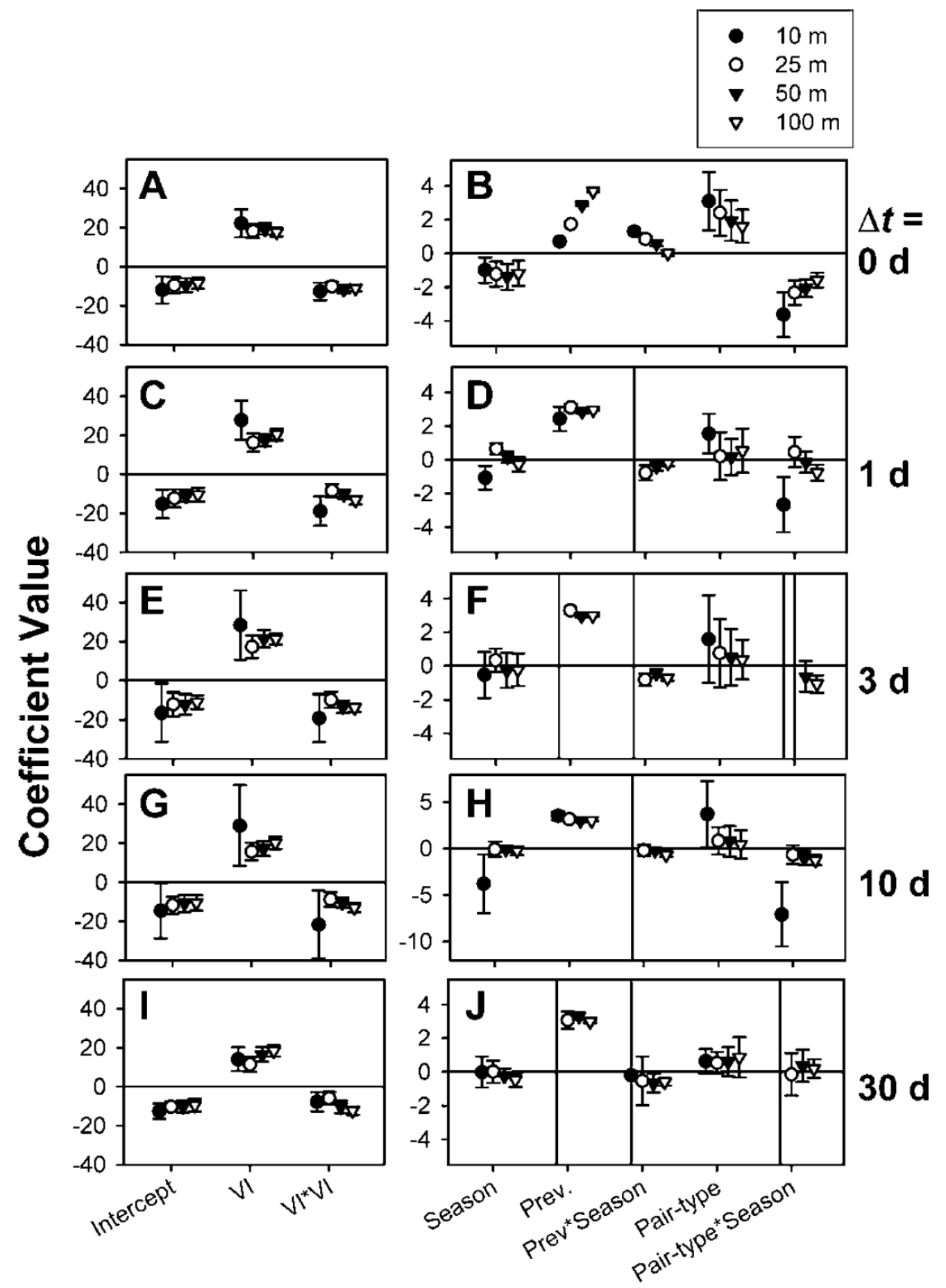


674 


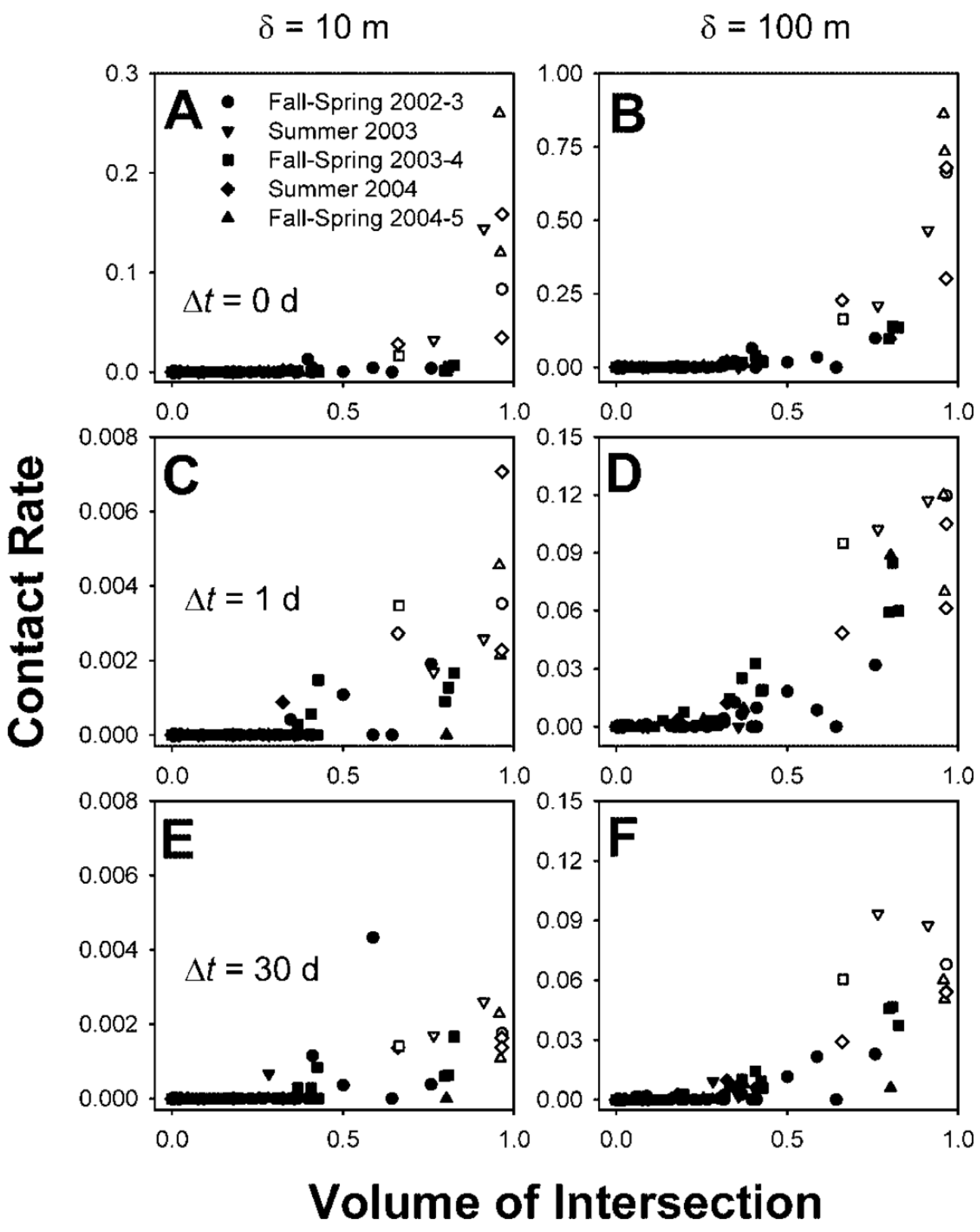

675

676 


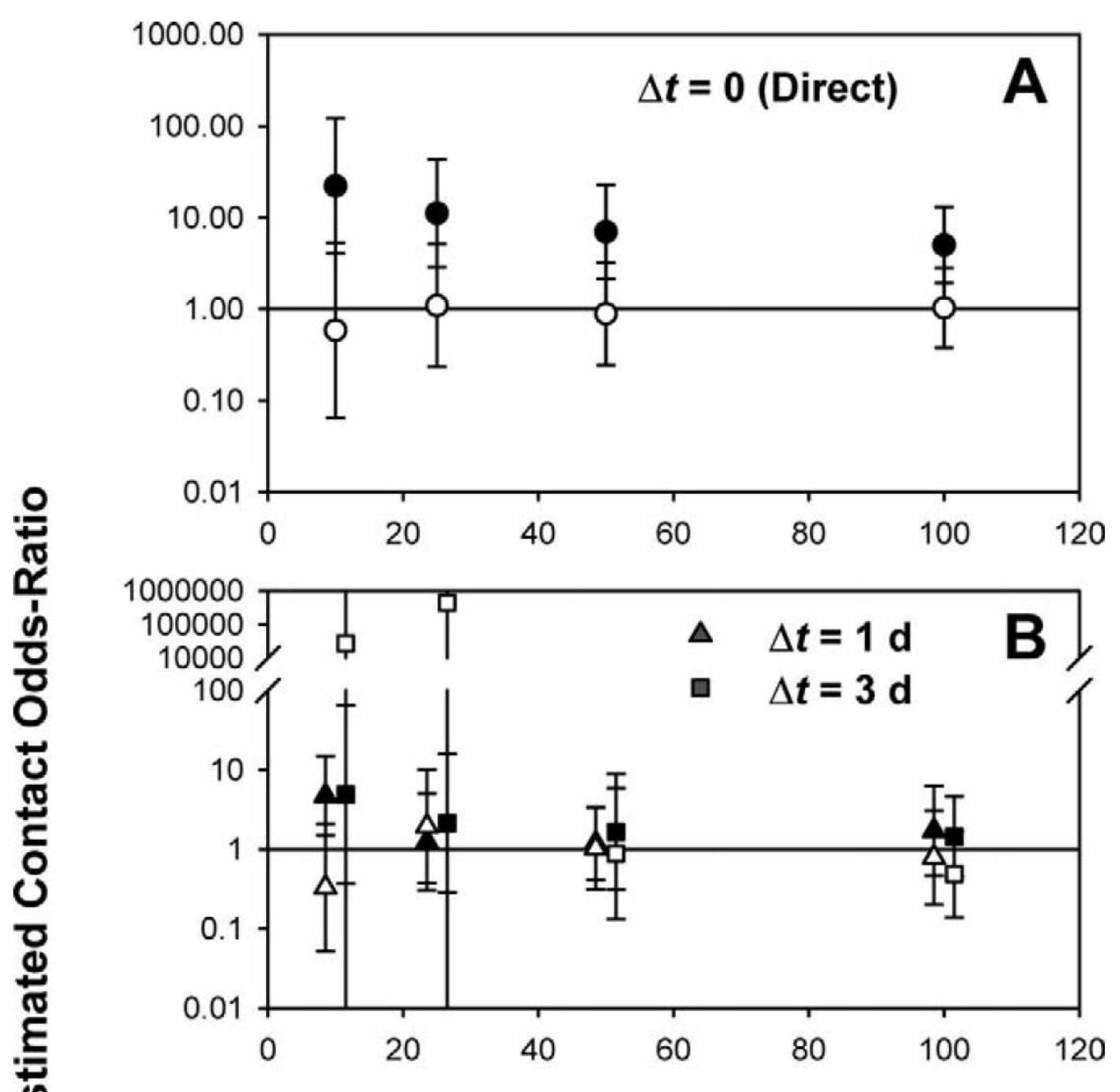

ய

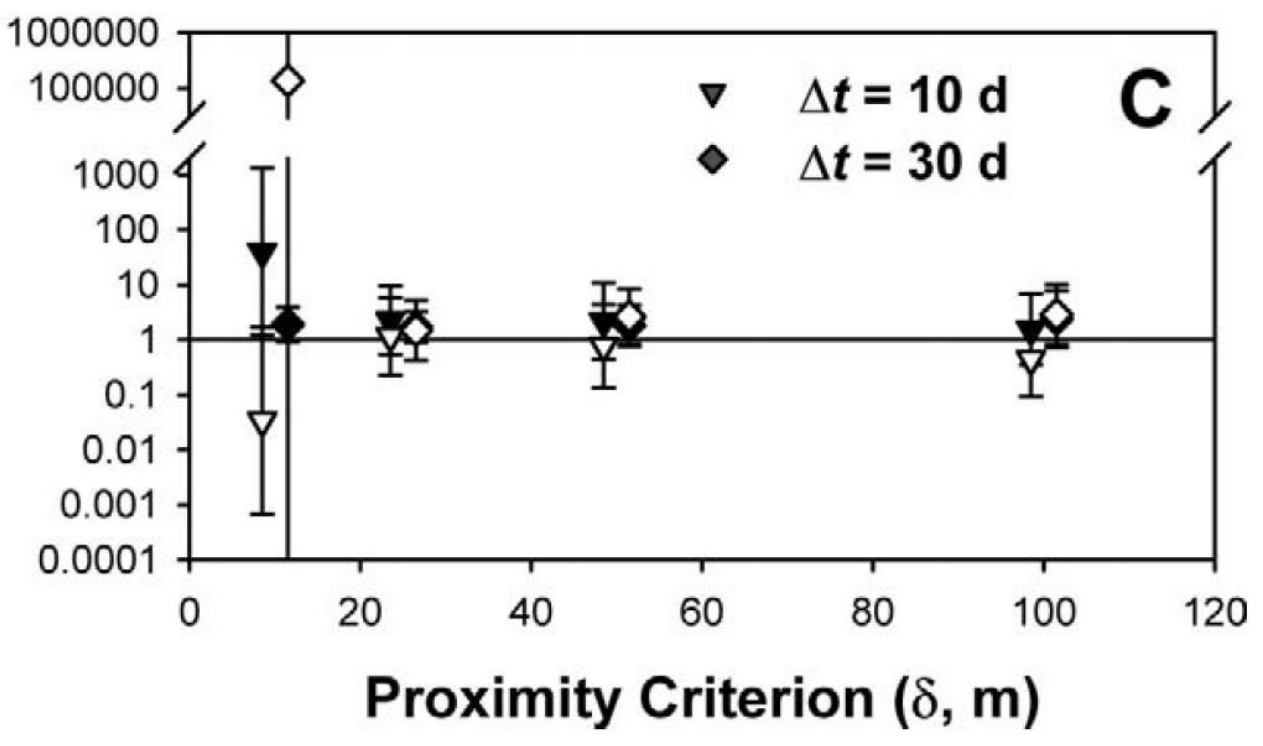

